\title{
The 2004 Sumatra tsunami as recorded on the Atlantic coast of South America
}

\author{
R. N. Candella ${ }^{1}$, A. B. Rabinovich ${ }^{2,3}$, and R. E. Thomson ${ }^{3}$ \\ ${ }^{1}$ Instituto de Estudos do Mar Almirante Paulo Moreira, 253 Rua Kioto, Arraial do Cabo, RJ, 28930-000, Brazil \\ ${ }^{2}$ P. P. Shirshov Institute of Oceanology, 36 Nakhimovsky Pr., Moscow, 117997, Russia \\ ${ }^{3}$ Institute of Ocean Sciences, 9860 West Saanich Road, Sidney, British Columbia, V8L 4B2, Canada
}

Received: 4 July 2007 - Revised: 26 September 2007 - Accepted: 4 October 2007 - Published: 2 January 2008

\begin{abstract}
The 2004 Sumatra tsunami propagated throughout the World Ocean and was clearly recorded by tide gauges on the Atlantic coast of South America. A total of 17 tsunami records were found and subsequently examined for this region. Tsunami wave heights and arrival times are generally consistent with numerical modeling results. Maximum wave heights of more than $1.2 \mathrm{~m}$ were observed on the coasts of Uruguay and southeastern Brazil. Marked differences in tsunami height from pairs of closely located tide gauge sites on the coast of Argentina illustrate the importance that local topographic resonance effects can have on the observed wave response. Findings reveal that, outside the Indian Ocean, the highest waves were recorded in the South Atlantic and not in the Pacific as has been previously suggested.
\end{abstract}

\section{Introduction}

The $M_{w}=9.3$ megathrust earthquake of 26 December 2004 off the coast of Sumatra (Fig. 1a) generated a catastrophic tsunami that caused widespread damage in coastal areas of the Indian Ocean and killed over 230000 people (Satake et al., 2007). Tsunami waves were subsequently recorded by a large number of tide gauges throughout the World Ocean, including near-source regions of the Indian Ocean (cf. Merrifield et al., 2005; Rabinovich and Thomson, 2007) and remote regions of the Pacific and Atlantic oceans (Titov et al., 2005; Rabinovich et al., 2006; Thomson et al., 2007). The event was unprecedented in its global reach (Titov et al., 2005; Geist et al., 2006).

Tsunamis in the Atlantic Ocean are not as common as in the Pacific Ocean. The few known tsunami records for the Atlantic include those generated by the 1883 Krakatau Volcano explosion (Indonesia) (cf. Pelinovsky et al., 2005)

Correspondence to: R. E. Thomson

(thomsonr@dfo-mpo.gc.ca) and by several local earthquakes (cf. Baptista et al., 1992; Lockridge et al., 2001; Fine et al., 2005). So infrequent are tsunamis in the Atlantic that, in the period immediately following the 2004 Sumatra tsunami, few experts had expected that this tsunami would be recorded outside the Indian Ocean. Nevertheless, a few days after the earthquake, tsunami waves were identified in several tide gauge records on the coast of North America (Department of Fisheries and Oceans, Institute of Ocean Sciences, Sidney, BC, Canada, 2005, http://www-sci.pac.dfo-mpo.gc.ca/ osap/projects/tsunami/tsunamiasia_e.htm; also Rabinovich et al. (2006) and Thomson et al. (2007)). The 2004 tsunami was also detected in several records from the South and Central Atlantic, in particular, at Signy (South Orkney Islands), Port Stanley (Falkland Islands) and St. Helena (Woodworth et al., 2005) and at Takoradi, west coast of equatorial Africa (Joseph et al., 2006) (Fig. 1a). Global tsunami propagation models (Titov et al., 2005; Kowalik et al., 2007) demonstrate that the Mid-Atlantic Ridge served as a wave-guide, efficiently transmitting tsunami energy from the source area to far-field regions of the Atlantic Ocean.

Detection of the 2004 tsunami on the Atlantic coast of South America includes sites in Brazil (Candella, 2005; Melo and Rocha, 2005; França and de Mesquita, 2007) and Argentina (Dragani et al., 2006), regions where tsunamis had never been recorded previously. For those records in which tsunami were detected, the tsunami signal was distinct and yielded preliminary estimates of measured arrival times that were in reasonable agreement with calculated arrival times (cf. França and de Mesquita, 2007). Moreover, at two Brazilian sites, Imbituba and Ubatuba (Fig. 1b), the observed tsunami trough-to-crest heights were more than $1 \mathrm{~m}$ (Melo and Rocha, 2005; França and de Mesquita, 2007), higher than at any other site outside the Indian Ocean.

Years after the event, records of the 2004 tsunami are still being collected and archived. Several additional records have now been found for the Atlantic coast of South America.

Published by Copernicus Publications on behalf of the European Geosciences Union. 

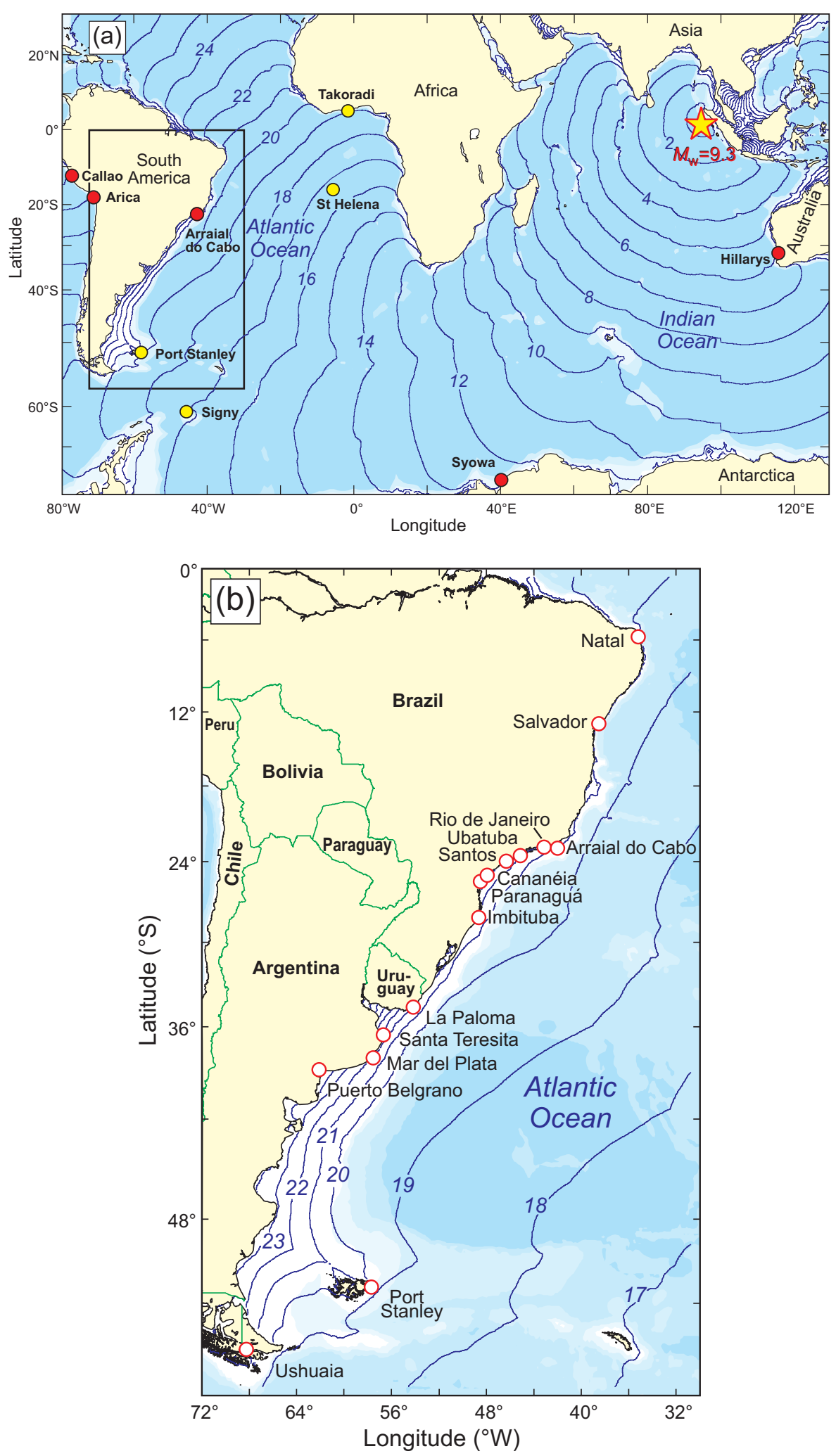

Fig. 1. (a) Map of the Indian and Atlantic oceans showing the location of the $M_{w}=9.3$ earthquake epicenter (star) and positions of selected tide gauges. Red circles indicate tide gauges which were used to estimate the wave height attenuation coefficient as a function of tide gauge sampling interval. Solid thin lines are hourly isochrones of the tsunami travel time from the source area. (b) Detail of the rectangular region in (a) showing the Atlantic coast of South America with positions of tide gauges. Isochrones are as in (a). 
Table 1. Locations of tide gauge recordings of the 2004 Sumatra tsunami on the Atlantic coast of South America.

\begin{tabular}{|c|c|c|c|c|c|c|}
\hline \multirow[t]{2}{*}{ No. } & \multirow[t]{2}{*}{ Stations } & \multirow[t]{2}{*}{ Country } & \multirow[t]{2}{*}{ Gauge Type } & \multirow[t]{2}{*}{ Sampling interval (min) } & \multicolumn{2}{|c|}{ Coordinates } \\
\hline & & & & & Latitude (S) & Longitude (W) \\
\hline 1 & Port Stanley, Falkland Is. & UK & Digital & 15 & $51^{\circ} 45.0^{\prime}$ & $57^{\circ} 56.0^{\prime}$ \\
\hline 2 & Ushuaia 1 & Argentina & Digital & 15 & $54^{\circ} 49.0^{\prime}$ & $68^{\circ} 18.0^{\prime}$ \\
\hline 3 & Ushuaia 2 & Argentina & Digital & 6 & $54^{\circ} 49.0^{\prime}$ & $68^{\circ} 13.0^{\prime}$ \\
\hline 4 & Puerto Belgrano & Argentina & Analog & $4^{*}$ & $38^{\circ} 54.0^{\prime}$ & $62^{\circ} 06.0^{\prime}$ \\
\hline 5 & Mar del Plata 1 & Argentina & Analog & $4^{*}$ & $38^{\circ} 05.9^{\prime}$ & $57^{\circ} 31.0^{\prime}$ \\
\hline 6 & Mar del Plata 2 & Argentina & Analog & 6 & $38^{\circ} 02.0^{\prime}$ & $57^{\circ} 31.5^{\prime}$ \\
\hline 7 & Santa Teresita & Argentina & Digital & 6 & $36^{\circ} 32.9^{\prime}$ & $56^{\circ} 40.0^{\prime}$ \\
\hline 8 & La Paloma & Uruguay & Digital & 15 & $34^{\circ} 39.2^{\prime}$ & $54^{\circ} 08.5^{\prime}$ \\
\hline 9 & Imbituba & Brazil & Analog & - & $28^{\circ} 13.0^{\prime}$ & $48^{\circ} 39.0^{\prime}$ \\
\hline 10 & Paranaguá & Brazil & Analog & $10^{*}$ & $25^{\circ} 30.1^{\prime}$ & $48^{\circ} 31.5^{\prime}$ \\
\hline 11 & Cananéia & Brazil & Analog & $2 *$ & $25^{\circ} 01.0^{\prime}$ & $47^{\circ} 55.5^{\prime}$ \\
\hline 12 & Santos & Brazil & Analog & $10^{*}$ & $23^{\circ} 57.3^{\prime}$ & $46^{\circ} 18.6^{\prime}$ \\
\hline 13 & Ubatuba & Brazil & Analog & $2 *$ & $23^{\circ} 30.0^{\prime}$ & $45^{\circ} 07.3^{\prime}$ \\
\hline 14 & Rio de Janeiro & Brazil & Analog & $10^{*}$ & $22^{\circ} 53.0^{\prime}$ & $43^{\circ} 08.1^{\prime}$ \\
\hline 15 & Arraial do Cabo & Brazil & Digital & 1 & $22^{\circ} 58.3^{\prime}$ & $42^{\circ} 00.9^{\prime}$ \\
\hline 16 & Salvador & Brazil & Digital & 6 & $12^{\circ} 58.4^{\prime}$ & $38^{\circ} 31.0^{\prime}$ \\
\hline 17 & Natal & Brazil & Analog & $5^{*}$ & $5^{\circ} 46.7^{\prime}$ & $35^{\circ} 12.5^{\prime}$ \\
\hline
\end{tabular}

* Sampling interval of records after digitization from float-type analog tide gauges.

Unfortunately, there were comparatively few sites in the tide gauge network in operation in this region at the time of the event and the instruments used in the network were mainly old technology. Nevertheless, in all tide gauge records examined, except two (Puerto Madryn, Argentina, and Bacuriteua, Brazil), tsunami waves were clearly identified, indicating that the 2004 tsunami was observed along the entire South American coast, from Tierra del Fuego in the south to northeastern Brazil in the north. Most of the data from these gauges remain unprocessed and unpublished. The purpose of the present study is to provide an overview of all available records for the 2004 Sumatra tsunami for the Atlantic coast of South America and to present fundamental statistics for the observed waves. This study was partly initiated by the Working Group on Tide Gauge Measurements of the 2004 Sumatra Tsunami, IUGG Tsunami Commission, and continues previous studies of this Group (cf. Rabinovich et al., 2006; Rabinovich and Thomson, 2007; Thomson et al., 2007).

\section{Observations}

The Atlantic Ocean historically has had no Tsunami Warning System and no standard instruments designed for tsunami measurements. Unlike the Pacific Ocean, the Atlantic Ocean is not bordered by major subduction zones, which are the main source for large tsunamis (Lockridge et al., 2002; Gusiakov, 2006). The primary purpose of Atlantic tide gauges is the measurement of relatively low-frequency processes, such as tides, storm surges, and seasonal to climatic sea level vari- ations (Woodworth et al., 2005). For this reason, sea level measurements for the Atlantic coast of South America are made using analog or digital instruments with long sampling intervals (6-15 min). Moreover, the tide gauges are often installed at locations not optimal for recording tsunamis. The only high-quality, short (1 min) sampling interval, digital instrument which worked on this coast during the 2004 Sumatra event was the tide gauge of the Instituto de Estudos do Mar Almirante Paulo Moreira-IEAPM at Arraial do Cabo. The record for this location appears to be the only record of the 2004 Sumatra tsunami in the entire Atlantic Ocean having this short sampling interval.

For the present study, we attempted to collect all available tide gauge records for sites located along the Atlantic coast of South America. Altogether, we could find data from 16 mainland tide gauges (Table 1). The three Brazilian records - Rio de Janeiro, Ubatuba, and Cananeia described by França and de Mesquita (2007), plus an additional record from Santos - were provided us by Carlos França (Departamento de Oceanografia, Universidade de São Paulo, Brazil); three additional Brazilian records from Paranaguá, Salvador, and Natal, were obtained from the Centro de Hidrografía da Marinha-CHM, Brazil; an analog record from Imbituba was provided to us by Eloi Melo (Federal University of Santa Catarina, Brazil) (see Melo and Rocha, 2005) and the digital record from Arraial do Cabo was obtained from the Instituto de Estudos do Mar Almirante Paulo Moreira-IEAPM (Candella, 2005). Pedro Walfir M.Souza Filho and Ulf Mehlig (Mangrove Dynamics and Management Project) provided the Bacuriteua data. Argentinean tide gauge records, includ- 
ing those from the Mar del Plata, Santa Teresita and Puerto Belgrano gauge sites located on the continental shelf off Buenos Aires (see Dragani et al., 2006) and the Ushhuaia tide gauge located on the coast of Tierra del Fuego (Fig. 1b), were provided by Walter Dragani (Departamento Oceanografía, Servicio de Hidrografía, Buenos Aires, Argentina). Additionally, Mark Merrifield and Shikiko Nakahara from the University of Hawaii provided us with two Argentinean digital GLOSS stations, Mar del Plata and Ushhuaia, which were located at slightly different positions than the Servicio de Hidrografía stations and had significantly different tsunami signals ${ }^{1}$. Ernesto Forbes (Division Oceanografía Física, Montevideo, Uruguay) sent us the La Paloma record.

We note that almost all available tide gauges in operation on the Atlantic coast of South America during the 2004 event indicated the presence of tsunami waves. There were only two exceptions: Puerto Madryn (Argentina) and Bacuriteua (Brazil). The first tide gauge is located inside Nuevo Gulf, which is itself connected with the ocean by a narrow opening which helped shelter the gauge from the tsunami. This record is further complicated by the fact that tides in the gulf are high and tsunami waves (even if they were present) are not discernible in the analog record (Walter Dragani, personal communication, 2007). The Bacuriteua tide gauge is located deep inside Caeté Bay, Pará, $15 \mathrm{~km}$ from the ocean. A few other tide gauges on the coasts of Argentina and Brazil had 1-h sampling and, therefore, could not be used for tsunami detection. The southernmost station, Ushuaia, is located far from other mainland stations. However, there is a nearby United Kingdom tide gauge at Port Stanley, Falkland Islands (Fig. 1b, Table 1) which clearly recorded the 2004 Sumatra tsunami (Woodworth et al., 2005). This record has been analyzed for comparison with other sites (Table 1).

\section{Data analysis}

In general, our ability to detect tsunami waves in a tide gauge record depends strongly on the signal-to-noise ratio (the ratio between tsunami and background oscillations). For the 2004 Sumatra tsunami, this ratio in the Indian Ocean ranged from 40:1 to 20:1, so detection was straightforward (Merrifield et al., 2005; Rabinovich and Thomson, 2007). In contrast, the tsunami signal-to-noise ratio in the North Pacific and North Atlantic records ranged from 4:1 to 1:1, making tsunami detection more difficult (Rabinovich et al., 2006). Infragravity waves generated by nonlinear interaction of wind waves, and tsunami-like, atmospherically-induced seiches, create serious problems in identifying weak tsunamis (Rabinovich and Stephenson, 2004). In fact, one of the main purposes of any preliminary analysis of tide gauge data (de-tiding, detrending, low-pass and high-pass filtering) is to reduce the

\footnotetext{
${ }^{1}$ In the text, index " 1 " refers to the Servicio de Hidrografía (Argentina) Mar del Plata and Ushuaia stations and index " 2 " to the corresponding GLOSS stations.
}

background noise level and thereby improve the tsunami-tonoise ratio. For most records from the Atlantic coast of South America, this ratio ranged from 10:1 to 4:1, making detection of tsunami waves relatively easy. However, at certain stations - specifically, Natal, Cananéia, Paranaguá, and Puerto Belgrano - the signal-to-noise ratio was relatively small (2:1 to 2.5:1), making identification of the exact arrival times of the tsunami problematical.

Several criteria were used to delineate arrival times of the first wave: (1) relatively sharp amplification and abrupt temporal structural changes in the observed longwave oscillations; (2) agreement among nearby stations (it was much easier to detect tsunami wave arrival for a group of stations than for a single tide gauge); (3) agreement between the expected tsunami wave arrival times and the observed times of arriving tsunami waves; and (4) the presence of dominant periods in the arriving waves (observations in the Indian and Pacific oceans indicate that the dominant periods of the 2004 tsunami were 30-60 min; Rabinovich et al., 2006; Rabinovich and Thomson, 2007). Tides, which are significant at most stations, were estimated using the least squares method of harmonic analysis and then subtracted from the original series. The residual (de-tided) time series were used in all subsequent analyses. To isolate the tsunami frequency band and simplify tsunami detection, we high-pass filtered the residual tide gauge series following application of a 4-h Kaiser-Bessel window. These filtered series were then used to construct plots of tsunami records for various sites and to estimate statistical characteristics of the waves.

Sixteen de-tided and high-pass filtered records (all records except for Imbituba) are presented in Fig. 2. Tsunami waves are clearly visible in most records. Tsunami arrival times are mutually consistent and agree reasonably well with estimated travel times (Fig. 1). The strongest tsunami oscillations were observed at Ubatuba, Arraial do Cabo, Santos, Salvador and La Paloma. In contrast, at Natal, Cananéia, Paranaguá, Mar del Plata 1 and Puerto Belgrano, the measured waves were relatively small. (All records presented in Fig. 2 have the same relative sea level scale to permit direct comparison of the tsunami wave heights at the various sites.) For those sites with relatively weak oscillations, it is difficult to recognize details of the tsunami wave structure. For this reason, we separated the sixteen sites into four groups and for each of these groups used a suitable plotting scale (Fig. 3a-d). This makes it possible to distinguish important wave features in the individual records.

Omitted from Fig. 2 is the record for Imbituba. The tide gauge at this site is a traditional analog ("pen-and-paper") instrument operated by Companhia Docas de Imbituba. Candido Jorge, the chief engineer of the Imbituba port, kindly provided this record to the Marine Hydraulics Laboratory (MHL) of the Federal University of Santa Catarina (this was probably the first gauge to demonstrate the arrival of the 2004 tsunami on the Atlantic coast of South America). Unfortunately, the gauge paper speed was very low, making it diffi- 
cult to digitize the entire record in detail. Nevertheless, Melo and Rocha (2005) from MHL were able to estimate wave heights and found that the maximum wave (the "queen wave" in their terminology) had a trough-to-crest height of $1.22 \mathrm{~m}$. We re-digitized the record peaks and troughs and obtained a similar value for the maximum wave height of $1.23 \mathrm{~m}$. A copy of a selected segment of the Imbituba analog tsunami record (simultaneous with other records) is shown in Fig. 3e. Because we did not have this record in digital form, we could not subtract the tides and high-pass filter the record. Despite this, the general structure of the waves measured at this site is well-defined and the record can be used to approximate a number of statistical wave parameters (Table 2). The main tsunami features evident in the records in Figs. 2 and 3 are:

1. The arrival of tsunami waves at most sites was relatively abrupt and unambiguously delineated.

2. The first recorded wave at most sites was positive, in good agreement with the notion that the first wave crest propagated from the source area in the Indian Ocean westward and southwestward; i.e. toward the Atlantic Ocean (cf. Lay et al., 2005; Titov et al., 2005; Rabinovich and Thomson, 2007).

3. Maximum waves at all stations except Port Stanley and Santa Teresita occurred several hours after arrival of the first wave.

4. All records had long ( $>2.5$ days) ringing times.

5. The recorded oscillations were polychromatic, with different periods for different sites, but with general dominance of 30-60 min period waves at most sites.

The principal statistical features of the tsunami waves observed at the 17 sites are presented in Table 2. Some parameters for three Argentinean and five Brazilian sites had been estimated previously (Candella, 2005; Melo and Rocha, 2005; França and de Mesquita, 2007; and Dragani et al., 2006). However, for the present study we carefully reexamined all data and have specified the corresponding estimates. The main difference from previous estimates is in the estimated arrival/travel times (compare Table 2 with Table 1 of Dragani et al., 2006) which are, in turn, directly related to confusion in which time zone (UTC versus local time) was used for a particular record. Another problem is the relatively high noise level at some sites (e.g. Puerto Belgrano) associated with local seiches which create problems in identifying tsunami waves. The opposite situation occurs when the sudden arrival of tsunami waves (whose heights are significantly greater than the background waves) distort the output from the high-pass filters. This abrupt change in wave energy is analogous to the Heaviside step function. Filtering such an abruptly changing time series (or a single peak wave, which is similar to a Dirac delta-function) will create erroneous oscillations in the time period preceding the arrival

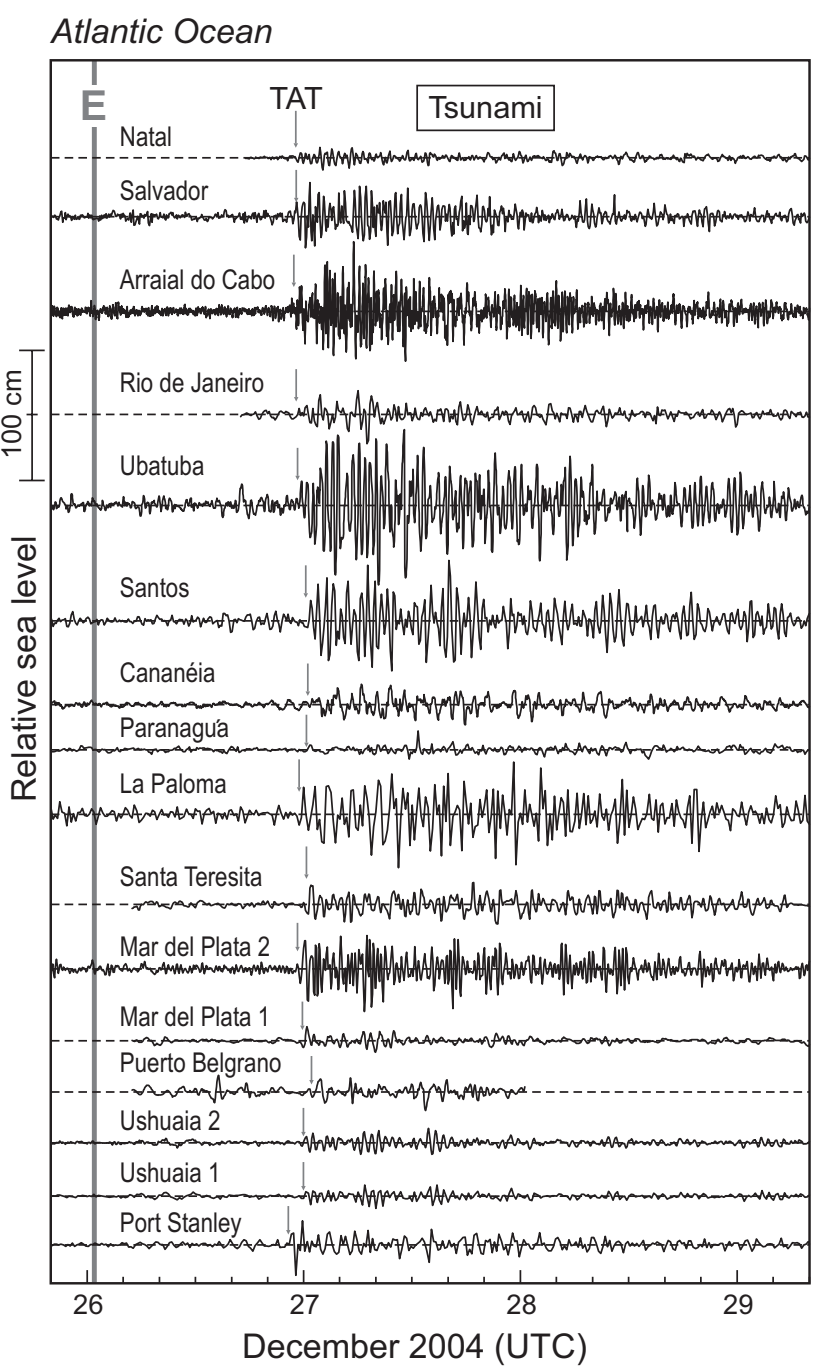

Fig. 2. Residual, high-pass filtered longwave records for sixteen sites along the Atlantic coast of South America. Small arrows indicate Tsunami Arrival Times (TAT). The filter uses a 4-h KaiserBessel window.

of the tsunami oscillations ${ }^{2}$ (Emery and Thomson, 2003). In particular, the first negative semi-waves observed in the filtered records for Santa Teresita, Mar del Plata, Santos and La Paloma (Fig. 3) are erroneous. As a consequence, we used non-filtered residual series when estimating the sign of the first wave, as well as the arrival times and maximum crest wave heights (Table 2).

According to our analysis, the 2004 tsunami waves arrived

\footnotetext{
${ }^{2}$ High-pass or band-pass filters are widely used by tsunami scientists to suppress tides and to isolate tsunamis, often without taking into account possible erroneous effects introduced by the filtering. For example, a filtering of an occasional instrumental spike will create a train of artificial tsunami-like oscillations (Emery and Thomson, 2003), which can be erroneously identified as real tsunami waves (cf. Okada, 1995).
} 

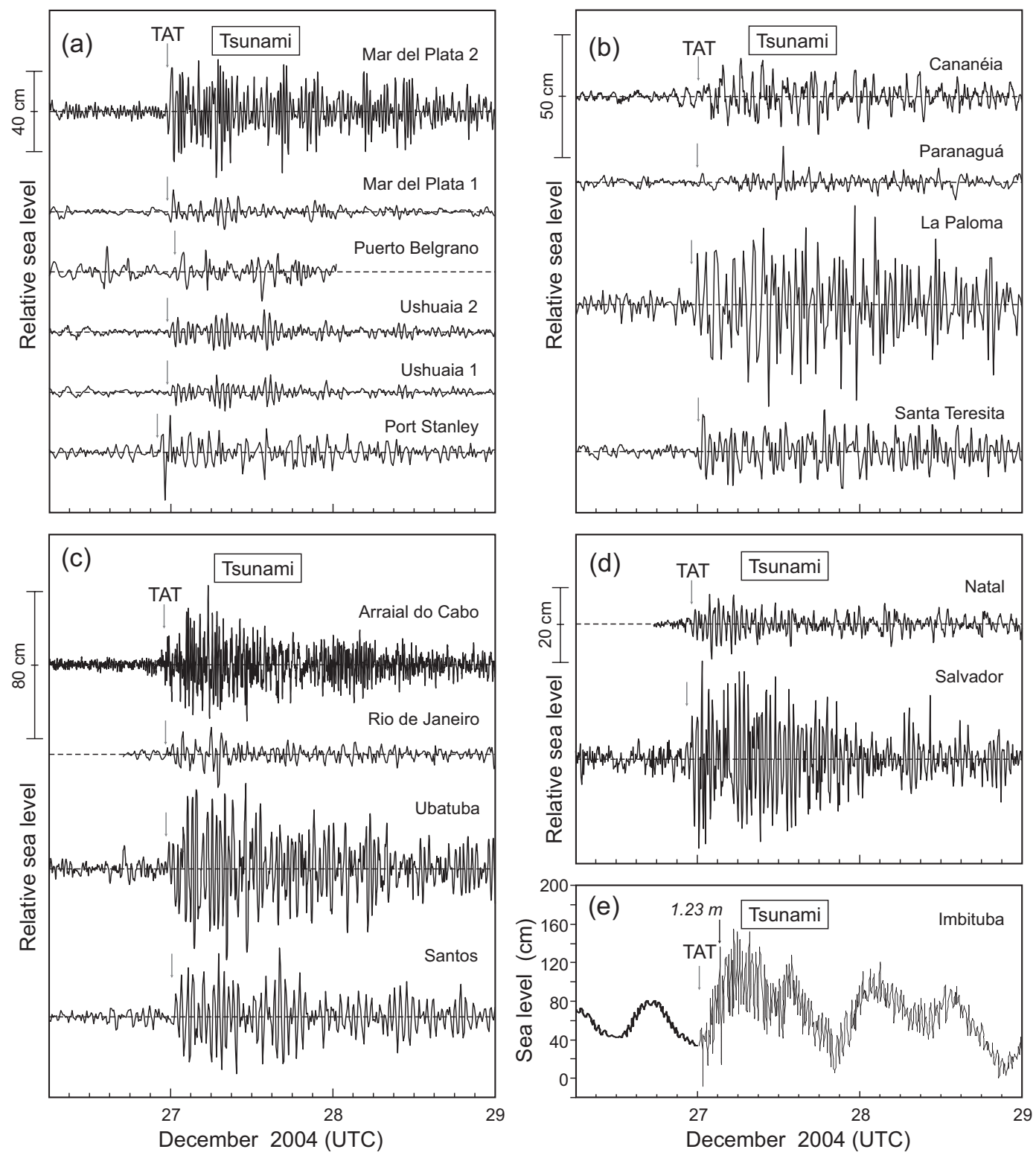

Fig. 3. (a-d) The same as in Fig. 2 but for four groups of stations for which there are different vertical scales for each group. (e) Copy of the analog tsunami record for Imbatuba. Small arrow pointing to " $1.23 \mathrm{~m}$ " indicates the maximum recorded wave.

on the Atlantic coast of South America between 22:12 (UTC) on 26 December (Salvador) and 01:16 (UTC) on 27 December (Puerto Belgrano). These waves had propagated from the source area near Sumatra in the Indian Ocean to the South American coast in approximately 21.2 to $24.2 \mathrm{~h}$. These times are in close agreement with estimated travel times of about $21 \mathrm{~h}$ for the northeastern coast of Brazil, 22 hours for the central and southern coast of Brazil, and $23 \mathrm{~h}$ for the coast of Argentina (Fig. 1b). The sign of the first wave was negative at only one station, Natal, located at the northeastern corner of South America. At three other sites, Puerto Belgrano, Cananéia, and Rio de Janeiro, the sign of the first wave was not well defined but appears to have been positive. At the other 11 stations, the first wave was definitely positive (Table 2). Maximum wave heights varied from $17-18 \mathrm{~cm}$ at Ushuaia 1, Mar del Plata 1, Natal and Paranaguá to $123 \mathrm{~cm}$ at Imbituba and $114 \mathrm{~cm}$ at Ubatuba. The last two wave heights represent the highest values for the 2004 tsunami recorded outside the Indian Ocean. Only at three sites (Port Stanley, Santa Teresita and Salvador) were maximum wave heights observed within $3 \mathrm{~h}$ of the first wave arrival times. At all other sites, maximum waves occurred about 6 to $12 \mathrm{~h}$ after the first arrival and in La Paloma more than one day after the first wave (Fig. 3b). 
Table 2. Characteristic features of the 2004 Sumatra tsunami determined from tide gauge records on the Atlantic coast of South America.

\begin{tabular}{|c|c|c|c|c|c|c|c|c|c|c|}
\hline \multirow[t]{2}{*}{ Station } & \multicolumn{4}{|c|}{ First wave } & \multicolumn{4}{|c|}{ Maximum wave } & \multicolumn{2}{|c|}{ Significant wave } \\
\hline & $\begin{array}{l}\text { Arrival } \\
\text { day/mon }\end{array}$ & $\begin{array}{l}\text { Arrival time } \\
\text { (UTC) }\end{array}$ & $\begin{array}{l}\text { Travel time } \\
\text { (h:min) }\end{array}$ & Sign & Arrival day & $\begin{array}{l}\text { Arrival time } \\
\text { (UTC) }\end{array}$ & $\begin{array}{l}\text { Observed } \\
\text { height } \\
(\mathrm{cm})\end{array}$ & $\begin{array}{l}\text { Corrected } \\
\text { height } \\
(\mathrm{cm})\end{array}$ & $\begin{array}{c}\text { Observed } \\
\text { height } \\
(\mathrm{cm})\end{array}$ & $\begin{array}{c}\text { Corrected } \\
\text { height } \\
(\mathrm{cm})\end{array}$ \\
\hline Port Stanley & $26 / 12$ & $22: 30$ & $21: 31$ & + & $26 / 12$ & 23:08 & 44 & 86 & 15.2 & 27.1 \\
\hline Ushuaia 1 & $27 / 12$ & 00:07 & $23: 08$ & + & $27 / 12$ & $06: 45$ & 17 & 33 & 9.6 & 17.1 \\
\hline Ushuaia 2 & $27 / 12$ & 00:00 & $23: 01$ & + & $27 / 12$ & $13: 48$ & 20 & 24 & 10.2 & 11.9 \\
\hline Mar del Plata 2 & $27 / 12$ & 00:09 & $23: 10$ & + & $27 / 12$ & $06: 42$ & 59 & 72 & 32.9 & 38.3 \\
\hline Santa Teresita & $27 / 12$ & $00: 33$ & $23: 34$ & + & $27 / 12$ & $00: 48$ & 31 & 38 & 19.0 & 22.1 \\
\hline La Paloma & $26 / 12$ & $23: 45$ & $22: 46$ & + & $27 / 12$ & $23: 30$ & 80 & 157 & 44.6 & 79.4 \\
\hline Imbituba & $27 / 12$ & $00: 20$ & $23: 21$ & + & $27 / 12$ & $03: 20$ & 123 & 123 & 58.6 & 58.6 \\
\hline Paranaguá & $27 / 12$ & $00: 30$ & $23: 31$ & + & $27 / 12$ & $12: 40$ & 18 & 18 & 8.3 & 8.3 \\
\hline Cananéia & $27 / 12$ & $00: 48$ & $23: 49$ & $+?$ & $27 / 12$ & $06: 38$ & 31 & 31 & 10.2 & 10.2 \\
\hline Salvador & $26 / 12$ & $22: 12$ & $21: 13$ & + & $27 / 12$ & $00: 12$ & 51 & 62 & 26.5 & 30.8 \\
\hline Natal & $26 / 12$ & 23:09 & $22: 10$ & - & $27 / 12$ & $02: 07$ & 17 & 17 & 7.4 & 7.4 \\
\hline
\end{tabular}

Of particular interest are the differences in response for the two pairs of Argentinean stations located within a few kilometers of each other: (1) Ushuaia 1 and Ushuaia 2; and (2) Mar del Plata 1 and Mar del Plata 2. The records from the first pair (Ushuaia) look very similar (Fig. 3a) and have similar statistical parameters (Table 2). Because Ushuaia 2 is located approximately $5 \mathrm{~km}$ eastward from Ushuaia 1 (i.e., nearer to the source), it makes sense that the tsunami waves arrived at site 2 a few minutes earlier than at site 1. Maximum observed wave heights at these sites are also alike (17 and $20 \mathrm{~cm}$, respectively), the only difference being that at Ushuaia 1 the maximum height in the second train of waves was slightly higher than in the third train, while at Ushuaia 2 this was reversed. This difference is likely not due to any physical process but to the different in the sampling intervals at sites 1 and 2 (15 min and $6 \mathrm{~min}$, respectively).

For the second pair of stations (Mar del Plata), the situation is markedly different. In contrast to the records at Mar de Plata 1, the oscillations at Mar de Plata 2 were highly regular and monochromatic with a relatively short dominant period of about $25 \mathrm{~min}$ (Fig. 3a, Table 2). Although the wave arrival times for sites 1 and 2 are almost identical (00:04 and 00:09 UTC, respectively), the maximum wave height at site 2 of $59 \mathrm{~cm}$ was approximately 3.5 times larger than at site 1. These differences are apparently related to the fact that the Servicio de Hidrografía tide gauge (Mar del Plata 1) is located on a comparatively open coast whereas the GLOSS tide gauge (Mar del Plata 2) is situated inside an isolated harbour. The observed regular oscillations at site 2 appear to be eigen-oscillations of the harbour that were strongly ampli- fied by local resonance effects. Clearly, this pair of stations has yielded a fortuitous illustration of the pronounced influence that local topographic features can have on the observed heights of tsunami waves.

In addition to the usual maximum (trough-to-crest) waveheight $\left(H_{\max }\right)$ parameter, we have also examined the significant wave-height $\left(H_{1 / 3}\right)$ parameter, defined as the average height of the highest one-third of all the waves (LeBlond and Mysak, 1978). For the averaging period, we chose $48 \mathrm{~h}$. Thus, whereas $H_{\max }$ is a unique feature of the tsunami wave field, related to one specific peak value, $H_{1 / 3}$ is an integral measure of the tsunami wave field during the observational period. The highest significant heights $(>40 \mathrm{~cm})$ were observed at four sites: Imbituba, La Paloma, Ubatuba and Santos.

The ratio, $r=H_{1 / 3} / H_{\max }$, is representative of the rate of tsunami energy decay, which is slow for large $r$ and fast for small $r$. For most records $r \approx 0.3-0.5$. The largest $r \approx 0.61$ is for Santos and Santa Teresita indicating slow energy decay at these sites (Fig. 3c), while the smallest $r \approx 0.30$ is for Arraial do Cabo, where the tsunami energy decays rapidly.

\section{Effect of tide gauge sampling interval}

Statistical properties of the tsunami records were discussed in the previous section without taking into account the response characteristics of the individual tide gauges. As indicated by Table 1, about one half of all tide gauges used in the present study are digital, but with widely different sampling intervals, ranging from $1 \mathrm{~min}$ at Arraial do Cabo to 


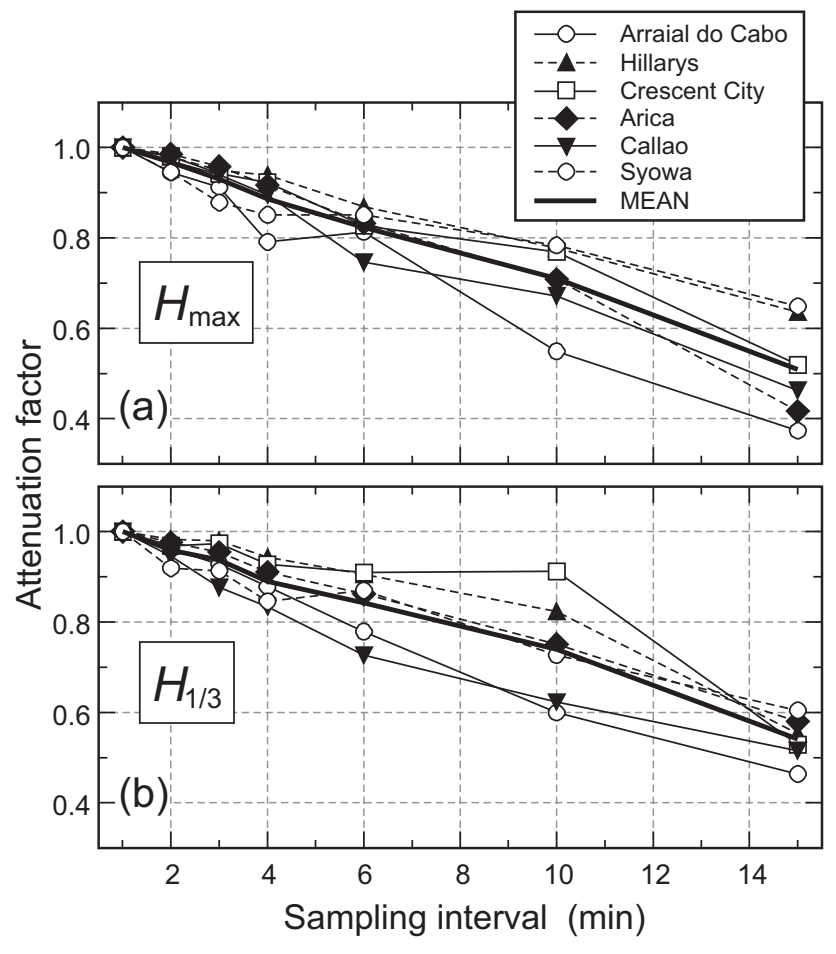

Fig. 4. (a) Attenuation factor (coefficient) $R_{\max }^{k}(j)$ for maximum wave heights as functions of the sampling interval $(j=1,2,3,4,6$, 10 , and $15 \mathrm{~min}$ ) at six selected stations. Also shown is the mean attenuation coefficient averaged over six stations. (b) As in (a) but for attenuation coefficient $R_{1 / 3}^{k}(j)$ for the significant wave height. Results demonstrate the effect of sampling time interval on the wave parameters.

15 min at Port Stanley, Ushuaia 1 and La Paloma. It is obvious that long sampling intervals can lead to a marked distortion of the wave properties. Waves are not well represented if the sampling interval is long relative to the actual wave periods. The resulting aliasing can significantly affect the statistical results, especially maximum wave height (Emery and Thomson, 2003). The influence of sampling interval on recorded tsunami wave parameters depends on two primary factors: (1) the frequency and energy content of the incoming waves; and (2) the frequency response of the observational site. The first is known fairly well for each event, while the second depends on the local topographic admittance function, which cannot be estimated without high-quality observations with short sampling interval (cf. Rabinovich and Stephenson, 2004) or detailed numerical modeling (Raichlen et al., 1983).

Because of the long sampling intervals of the gauges, it was not possible to directly quantify exact tsunami wave heights for each measurement site. To improve our statistical estimates of the wave parameters, we have therefore attempted to account for the attenuation of the recorded 2004 tsunami as a function of instrument sampling interval. For this purpose, we selected six representative continental stations that have short sampling times and relatively strong tsunami signals; island stations were not considered since they likely have different wave responses than the continental stations. Five of these stations (Syowa, Japanese Antarctic station with 30-s sampling; Arraial do Cabo, Brazil, 1min sampling; Hillarys, Australia, 1-min sampling; Callao, Peru, 2-min sampling; and Arica, Chile, 2-min sampling) are indicated by the red circles in Fig. 1a. The sixth station (Crescent City, California, 1-min sampling) is located in the North Pacific and cannot therefore be presented on the map. To demonstrate how maximum and significant wave heights can be attenuated by large sampling intervals, we interpolated, averaged, and then resampled these six records with 1, 2, 3, 4, 6, 10 and 15-min intervals. The resampled series were then used to determine the corresponding statistical parameters for the tsunami waves (Tables 3 and 4). The attenuation factors (coefficients) $R_{\max }^{k}(j)$ and $R_{1 / 3}^{k}(j)$ for $k$-th station and sampling interval $j$ are defined through the ratios

$R_{\max , 1 / 3}^{k}(j)=H_{\max , 1 / 3}^{k}(j) / H_{\max , 1 / 3}^{k}(1)$,

where $H_{\max , 1 / 3}^{k}(j)$ is the maximum (or significant) wave height for $j=2,3,4,5,6,10$ and $15 \mathrm{~min}$, and $H_{\max , 1 / 3}^{k}(1)$ is the respective height for $j=1 \mathrm{~min}$. Calculated factors $R_{\max }^{k}(j)$ and $R_{1 / 3}^{k}(j)$ for individual stations are shown in Fig. 4. Although results differ slightly from one site to another, there is a general consistency among the estimates. More specifically, the longer the sampling interval, the greater the attenuation of the recorded wave heights. The individual factors were subsequently used to calculate mean attenuation coefficients:

$R_{\max , 1 / 3}(j)=\frac{1}{n} \sum_{k=1}^{n} R_{\max , 1 / 3}^{k}(j)$,

where, for this study, $n=6$ (Fig. 4).

It is worth noting that the mean regression curves for both $H_{\max }$ and $H_{1 / 3}$ are almost straight lines, indicating an inverse linear relationship with sampling interval. For example, a 4min sampling interval leads to approximately $11 \%$ and $9 \%$ reductions in the maximum and significant wave heights, respectively. For a 10-min sampling, the corresponding attenuation factors are $29 \%$ and $22 \%$, while for 15 -min sampling, attenuation factors are $49 \%$ and $44 \%$, respectively (Tables 3 and 4). Note that these estimates are for the 2004 tsunami, which was large-scale and low-frequency. For smaller scale, high-frequency events, the attenuation coefficients heights would be much greater.

Because the sampling interval correction factor for each gauge site is not known, we use the mean attenuation coefficients, $R_{\max }$ and $R_{1 / 3}$ to correct the heights $H_{\max }$ and $H_{1 / 3}$ derived from digital long-sampling tide gauge records. We have not corrected analog records, since we have to assume that the wave heights were correctly reproduced during the original digitization. Results are presented in Table 2. The 
Table 3. Maximum trough-to-crest wave height, $H_{\max }(\mathrm{cm})$, obtained for selected re-sampling interval $(j)$. The last row is the mean attenuation coefficient $R_{\max }(j)$ defined by Eq. (2).

\begin{tabular}{llccccccc}
\hline Station & Country & \multicolumn{7}{c}{ Sampling interval, $j(\mathrm{~min})$} \\
& & 1 & 2 & 3 & 4 & 6 & 10 & 15 \\
\hline Arraial do Cabo & Brazil & 91 & 86 & 83 & 72 & 74 & 50 & 34 \\
Hillarys & Australia & 99 & 97 & 94 & 93 & 86 & 77 & 63 \\
Crescent City & USA & 52 & 51 & 49 & 48 & 43 & 40 & 27 \\
Arica & Chile & 72 & 71 & 69 & 66 & 60 & 51 & 30 \\
Callao & Peru & 67 & 65 & 63 & 60 & 50 & 45 & 31 \\
Syowa, Antarctic & Japan & 74 & 70 & 65 & 63 & 63 & 58 & 48 \\
Mean attenuation factor, $R_{\text {max }}$ & - & 1.00 & 0.97 & 0.93 & 0.89 & 0.82 & 0.71 & 0.51 \\
\hline
\end{tabular}

Table 4. Significant wave height, $H_{1 / 3}(\mathrm{~cm})$, for selected sampling interval $(j)$. The last row gives the mean attenuation coefficient $R_{1 / 3}(j)$ defined by Eq. (2).

\begin{tabular}{llccccccc}
\hline Station & Country & \multicolumn{7}{c}{ Sampling interval, $j$ (min) } \\
\hline & & 1 & 2 & 3 & 4 & 6 & 10 & 15 \\
\hline Arraial do Cabo & Brazil & 43.6 & 44.2 & 46.0 & 42.5 & 38.8 & 36.6 & 25.7 \\
Hillarys & Australia & 79.4 & 78.1 & 77.8 & 74.9 & 71.9 & 65.4 & 43.9 \\
Crescent City & USA & 38.6 & 37.4 & 37.6 & 35.8 & 35.1 & 35.2 & 20.4 \\
Arica & Chile & 41.4 & 40.4 & 39.5 & 37.7 & 35.7 & 31.1 & 24.0 \\
Callao & Peru & 44.6 & 42.2 & 39.1 & 37.2 & 32.4 & 27.8 & 23.0 \\
Syowa, Antarctic & Japan & 53.1 & 48.8 & 48.5 & 44.9 & 46.2 & 38.6 & 32.1 \\
Mean attenuation factor, $R_{1 / 3}$ & - & 1.00 & 0.97 & 0.96 & 0.91 & 0.86 & 0.78 & 0.56 \\
\hline
\end{tabular}

most important correction is for the La Paloma record. Here, the corrected value of $H_{\max }=157 \pm 12 \mathrm{~cm}$ is higher than at Imbituba and Ubatuba, and higher than any other observed or estimated 2004 tsunami wave height outside of the Indian Ocean. The significant wave height $H_{1 / 3}=79.4 \pm 1.8 \mathrm{~cm}$ for La Paloma is also considerably higher than for other stations.

Corrected maximum wave heights are shown in Fig. 5 together with numerically simulated wave heights for the 2004 tsunami (Titov et al., 2005). The observed and computed heights are in good agreement, and consistent with the "tongue" of high tsunami energy that extended from the Mid-Atlantic Ridge to the central Brazilian coast where it resulted in strong oscillations at Imbituba, Umbatuba, Arraial do Cabo and Santos. Stations in this region that recorded relatively small wave heights (Paranaguá, Cananéia and Rio de Janeiro) are located inside estuaries or bays that have narrow openings to the ocean. Another area exhibiting strong computed oscillations is the Uruguay shelf for which maximum wave heights were recorded at La Paloma. A second "tongue" of relatively high energy propagated along the American-Antarctic and Scotia ridges to the area of the Falkland Islands where strong oscillations were observed at Port Stanley. In contrast, the Titov et al. (2005) tsunami simulations indicate that little energy propagated to the northern Brazilian coast, in good agreement with observations at Natal where only $17 \mathrm{~cm}$ waves were recorded.
Because the numerical model of Titov et al. (2005) was a global model, it was unable to incorporate high resolution bathymetry near the coast. As a consequence, the model could not resolve small local effects and resonant amplifications as, for example, those observed in the area of Mar del Plata (see the records from the nearby tide gauges shown in Fig. 3a). Nested grids (cf. Cherniwsky et al., 2007) with fine-resolution of coast and bottom topography are needed for this problem.

\section{Temporal variations of tsunami energy}

The tsunami records in Fig. 3 exhibit a marked train structure. Several distinct wave trains with typical durations of 8 to $16 \mathrm{~h}$ appear in the records of Santa Teresita, Mar del Plata 1, Ushuaia 1 and 2 (Fig. 3a), La Paloma (Fig. 3b), Arraial do Cabo (Fig. 3c), Salvador (Fig. 3d) and in other records. It would appear that the tsunami wave trains and long ringing times were due to multiple wave reflections from continental boundaries. To examine this effect further, we estimated changes of tsunami wave energy as function of time. Tsunami variance was calculated over 6-h intervals with 4h overlaps (2-h shifts between estimates). Figure 6 shows the evolution of the tsunami energy for six selected sites on the South American coast. As observed for other tsunamis 


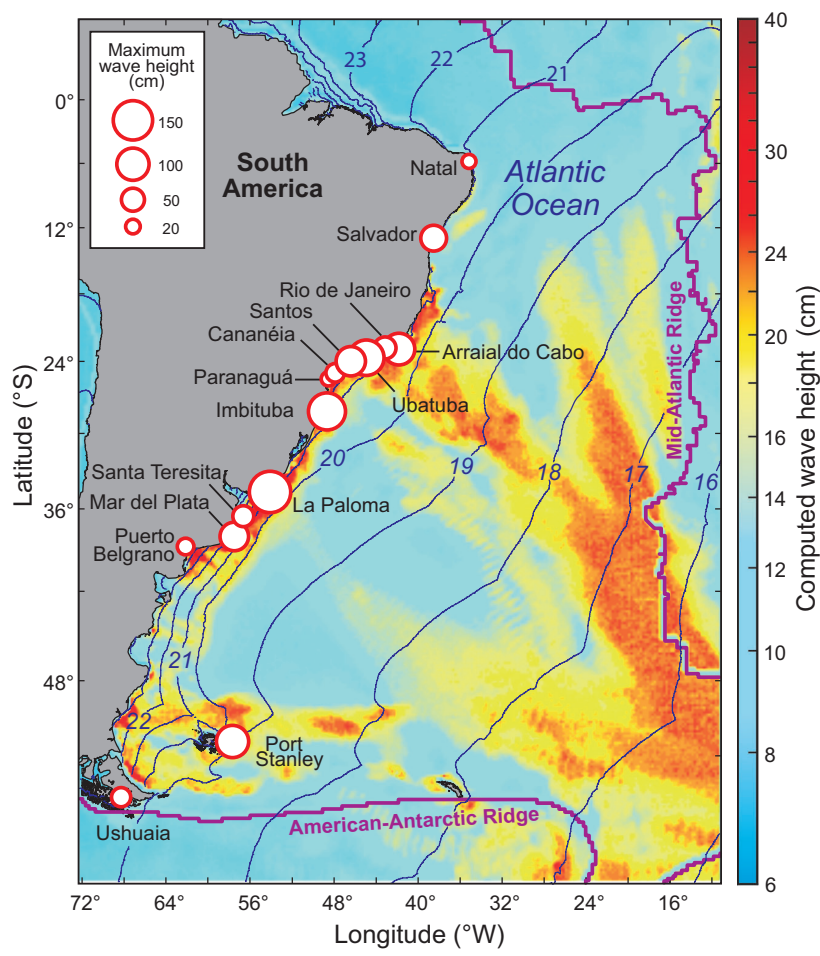

Fig. 5. Simulated tsunami wave heights from Titov et al. (2005) along with corrected maximum tsunami wave heights along the Atlantic coast of South America. Solid thin lines are hourly isochrones of the tsunami travel time from the source area.

(cf. Van Dorn, 1984, 1987), the wave energy has a general exponential decay with time (straight lines in Fig. 6). However, superimposed as this basic structure are broad "bursts" of wave energy indicative of additional pumping of tsunami energy from the open Atlantic Ocean. These bursts of energy have an obvious periodic structure. At Mar del Plata 1 and Santa Teresita, additional wave pumping occurs every $12 \mathrm{~h}$, while at Arraial do Cabo and Ubatuba it occurs every $18 \mathrm{~h}$. A similar effect was observed by Kowalik et al. (2007) for the Indian Ocean but with a reverberation time of only $2-3 \mathrm{~h}$. From their numerical model, Kowalik et al. (2007) were able to identify the specific coastline model elements responsible for tsunami wave reflection causing periodic energy fluxes in observed and simulated tsunamis. A similar study could be undertaken for the Atlantic Ocean. In the absence of specific modeling results, we speculate that the observed periodicity of the energy bursts (12 and $18 \mathrm{~h}$ for the coasts of Argentina and central Brazil, respectively), arises from energy pumping due to tsunami reflection from the coasts of Antarctic and Africa.

\section{Discussion and conclusions}

Although a few historical tsunami records were available for the North Atlantic prior to 2004 (cf. Baptista et al., 1994;

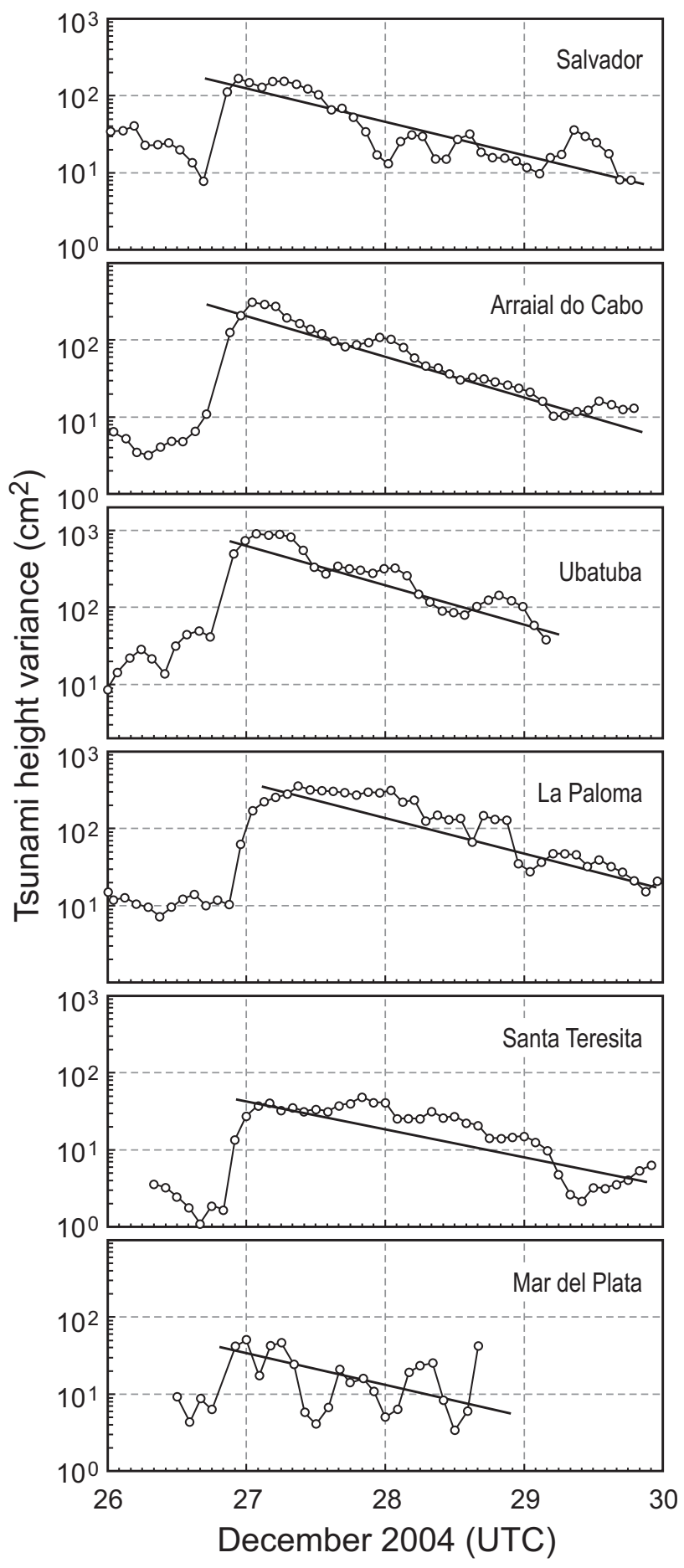

Fig. 6. Changes of tsunami wave variance with time for six selected sites on the Atlantic coast of South America (log-linear scale). Straight lines indicate the mean exponential energy decay.

Fine et al., 2005), the December 2004 Sumatra tsunami was the first event clearly recorded in the South Atlantic, and specifically, on the Atlantic coast of South America. We believe that we were able to locate most of the South American 
data for tide gauges which were operational during the 2004 event. These data cover almost the entire coast and show important characteristics of the wave phenomena. The high signal-to-noise ratio allowed for straightforward identification of the tsunami waves at all stations.

Of the 17 tide gauge records examined, nine were from analog ("pen-and-paper") instruments whose records had to be carefully digitized and analyzed. The six digital tide gauges used in the present study had sampling intervals ranging from 1 to $15 \mathrm{~min}$. In an attempt to evaluate the effects of sampling interval on recorded tsunami wave height, we examined six high-quality short-sampling records collected in various regions of the World Ocean and derived the mean attenuation coefficients for different sampling intervals. These factors were then used to standardize our statistical results and correct the recorded maximum and significant wave heights. According to our analysis, the highest tsunami waves were observed at La Paloma (maximum trough-to-crest wave height of $157 \mathrm{~cm})$, Imbituba $(122 \mathrm{~cm})$, Ubatuba $(114 \mathrm{~cm})$ and Arraial do Cabo $(91 \mathrm{~cm})$. All these values are significantly higher than maximum wave heights recorded at other stations in the Pacific Ocean (cf. Rabinovich et al., 2006). These observations refute early results by Murty et al. (2005) who, based on limited data available at that time, concluded that waves from the 2004 tsunami were much higher in the Pacific than in the Atlantic. According to Kowalik et al. (2007), the total inflow of 2004 tsunami energy into the Pacific Ocean was approximately $75 \%$ of the total energy inflow to the Atlantic Ocean. The smaller area of the Atlantic Ocean and the wave guide effect of the Mid-Atlantic Ridge promote additional intensification of tsunami waves in parts of the Atlantic Ocean. Global numerical simulation of the 2004 tsunami by Titov et al. (2005) demonstrate that waves generated during the event traveled southwestward from the source area in the Indian Ocean, curved around the southern tip of Africa and then propagated northward along the Mid-Atlantic Ridge. Upon reaching the Tropic of Capricorn, a branch of the ridge-trapped tsunami energy flux spit from the topographic wave guide and headed toward the coast of Brazil (striking the coast exactly where the maximum waves were observed) while another branch headed toward Nova Scotia (Geist et al., 2006). As revealed by the Titov et al. (2005) modeling results, the north coast of Brazil was in a "shadow" zone for the tsunami energy flux, explaining why low wave heights were recorded at Natal. In general, there is good agreement between the modeled and observed tsunami wave heights along the Atlantic coast of South America.

Tsunami records from closely spaced tide gauge stations exhibited marked differences in wave height, illustrating that regional seafloor topography strongly affected tsunami wave intensity on the coast. Because they are located inside bays (or estuaries), gauges at Cananéia, Paranaguá and Rio de Janeiro recorded much smaller waves from the 2004 tsunami than those at nearby Arraial do Cabo, Ubatuba and Santos.
In general, the tsunami energy was mainly concentrated on the southeast coast of South America, in accordance with the numerical results of Titov et al. (2005), with a decreasing trend from La Paloma to Natal. Distinct wave trains and long ringing times observed at most stations were apparently due to multiple wave reflections from continental boundaries, including the Antarctic coast and the coast of Africa.

Acknowledgements. We thank C. França (Departamento de Oceanografia, Universidade de São Paulo, Brazil), W. Dragani (Departamento Oceanografía, Servicio de Hidrografía, Buenos Aires, Argentina), E. Forbes (Division Oceanografía Física, Montevideo, Uruguay), R. Roso (Centro de Hidrografia da Marinha, Niteroi, Brazil), and M. Merrifield and S. Nakahara (University of Hawaii, Honolulu, USA) for providing the tide gauge data. We also thank V. Titov (PMEL/NOAA, Seattle, USA) and I. Fine (IOS, Sidney, Canada) for making available results of their numerical models, P. Kimber (Sidney, BC) and M. Krassovski (University of Victoria, $\mathrm{BC}$ ) for drafting the figures and $\mathrm{C}$. Wright for coordinating the electronic submissions. Partial support for ABR was provided by the Russian Foundation for Basic Research (RFBR) grants 05-05-64585 and 06-05-08108.

Edited by: P. Fabian

Reviewed by: two anonymous referees

\section{References}

Baptista, M. A., Miranda, P., and Mendes Victor, L.: Maximum entropy analysis of Portuguese tsunami data: The tsunamis of 28.02.1969 and 26.05.1975, Sci. Tsunami Hazards, 10(1), 9-20, 1992.

Candella, R. N.: Sea level at Arraial do Cabo, RJ, Brazil, http:// www.pmel.noaa.gov/tsunami/sumatra20041226.html, 2005.

Cherniawsky, J. Y, Titov, V. V., Wang, K., and Thomson, R. E.: Numerical simulation of tsunami waves and currents for southern Vancouver Island from a Cascadia megathrust earthquake, Pure Appl. Geophys., 164, 465-492, 2007.

Dragani, W. C., D’Onofrio, E. E., Grismeyer, W., and Fiore, M. E.: Tide gauge observations of the Indian ocean tsunami, December 26, 2004, in Buenos Aires coastal waters, Argentina, Cont. Shelf Res., 26, 1543-1550, 2006.

Emery, W. J. and Thomson, R. E.: Data Analysis Methods in Physical Oceanography, Second and revised edition, Elsevier, New York, 638 pp., 2003.

Fine, I. V., Rabinovich, A. B., Bornhold, B. D., Thomson, R. E., and Kulikov, E. A.: The Grand Banks landslide-generated tsunami of November 18, 1929: Preliminary analysis and numerical modeling, Mar. Geol., 215, 45-57, 2005.

França, C. A. S. and de Mesquita, A. R.: The December 26th 2004 tsunami recorded along the southeastern coast of Brazil, Nat. Hazards, 40, 209-222, 2007.

Geist, E .L., Titov, V. V., and Synolakis, C. E.: Wave of change, Scientific American, 56-63, January 2006.

Gusiakov, V. K.: Historical Tsunami Database for the Atlantic, Version 2.0, CD-ROM, Tsunami Laboratory, ICMMG RAS, Novosibirsk, Russia, 2006. 
Joseph, A., Odametey. J. T., Nikebi, E. K., et al.: The 26 December 2004 Sumatra tsunami recorded on the coast of West Africa, African J. Marine Science, 28(3/4), 705-712, 2006.

Kowalik, Z., Knight W., Logan T., and Whitmore P.: The tsunami of 26 December 2004: Numerical modeling and energy considerations, Pure Appl. Geophys., 164, 379-393, 2007.

Lay, T., Kanamori, H., Ammon, J. L., et al.: The Great SumatraAndaman earthquake of 26 December 2004, Science, 308, 1127 1133, 2005.

LeBlond, P. H. and Mysak, L. A.: Waves in the Ocean. Elsevier, Amsterdam, 602 pp., 1978.

Lockridge, P. A., Whiteside, L. S., and Lander, J. F.: Tsunamis and tsunami-like waves of the eastern United States, Sci. Tsunami Hazards, 20(3), 120-157, 2002.

Melo, E. and Rocha, C.: Sumatra tsunami detected in Southern Brazil, Maritime Hydraulics Laboratory, Federal University of Santa Catarina, Brazil, Unpublished Report, http://www.pmel. noaa.gov/tsunami/sumatra20041226.html, 2005.

Merrifield, M. A., Firing, Y. L., Aarup, T., et al.: Tide gage observations of the Indian Ocean tsunami, December 26, 2004, Geophys. Res. Lett., 32, L09603, doi:10.1029/2005GL022610, 2005.

Murty, T. S., Nirupama, N., Nistor, I., and Rao, A. D.: Leakage of the Indian Ocean tsunami energy into the Atlantic and Pacific Ocean, CSEG Recorder, December 2005, 33-36, 2005.

Okada, M.: Tsunami observation by ocean bottom pressure gauge, in: Tsunami: Progress in prediction, Disaster Prevention and Warning, edited by: Tsuchiya, Y. and Shuto, N., Kluwer, Dordrecht, 287-303, 1995.

Pelinovsky, E., Choi, B. H., Stromkov, A., Didenkulova, I., and Kim, H. S.: Analysis of tide-gauge records of the 1883 Krakatau tsunami, in: Tsunamis: Case Studies and Recent Developments, edited by: Satake, K., Springer, Dordrecht, 57-77, 2005.

Rabinovich, A. B. and Stephenson, F. E.: Longwave measurements for the coast of British Columbia and improvements to the tsunami warning capability, Nat. Hazards, 32(3), 313-343, 2004.
Rabinovich, A. B. and Thomson, R. E.: The 26 December 2004 Sumatra tsunami: Analysis of tide gauge data from the World Ocean. Part 1. Indian Ocean and South Africa, Pure Appl. Geophys., 164, 261-308, 2007.

Rabinovich, A. B., Thomson, R. E., and Stephenson, F. E.: The Sumatra Tsunami of 26 December 2004 as observed in the North Pacific and North Atlantic Oceans, Surv. Geophys., 27, 647-677, 2006.

Raichlen, F., Lepelletier, T. G., and Tam, C. K.: The excitation of harbors by tsunamis, in: Tsunamis - Their Science and Engineering, edited by: Iida, K. and Iwasaki, T., Terra Sci., Tokyo, 359-385, 1983.

Satake, K., Okal, E. A., and Borrero, J. C. Tsunami and its hazard in the Indian and Pacific oceans: Introduction, Pure Appl. Geophys., 164, 249-259, 2007.

Thomson, R. E., Rabinovich, A. B., and Krassovski, M. V.: Double jeopardy: Concurrent arrival of the 2004 Sumatra tsunami and storm-generated waves on the Atlantic coast of the United States and Canada, Geophys. Res. Lett., 34, L15607, doi:10.1029/2007GL030685, 2007.

Titov, V. V., Rabinovich, A. B., Mofjeld, H., Thomson, R. E., and González, F. I.: The global reach of the 26 December 2004 Sumatra tsunami, Science, 309, 2045-2048, 2005.

Van Dorn, W. G..: Some tsunami characteristics deducible from tide records, J. Phys. Oceanogr., 14, 353-363, 1984.

Van Dorn, W. G.: Tide Gauge Response to Tsunamis. Part II: Other Oceans and Smaller Seas, J. Phys. Oceanogr., 17, 1507-1516, 1987.

Woodworth, P. L., Blackman, D. L., Foden, P., et al.: Evidence for the Indonesian tsunami in British tidal records, Weather, 60(9), 263-267, 2005. 